Revista de Derecho

de la Pontificia Universidad Católica de Valparaíso

LIV (Valparaíso, Chile, 1er semestre de 2020)

[pp. 35 - 66]

\title{
LIBERTAD DE CONFIGURACIÓN Y CONTROL DE Constitucionalidad: el Parlamento y el Tribunal Constitucional desde la Teoría de los Derechos FUNDAMENTALES
}

[Legislative Configuration and Judicial Review: The Parliament and the Constitutional Court from the theory of constitutional rights]

\section{Antonio Leiva RabaeL* \\ Universidad de los Andes, Chile}

Resumen

Este trabajo presentar a las normas competenciales de derechos fundamentales como una propuesta desde lo que aquí se denomina la Teoría de los Derechos Fundamentales, para coordinar la libertad de configuración del Parlamento y el control de constitucionalidad. Se analizará esa teoría para sostener que la deliberación parlamentaria iusfundamental y el control de constitucionalidad se rigen por la Ponderación. Por ello, el respeto recíproco entre el Parlamento y Tribunal Constitucional, en esta materia, involucra la competencia y la ponderación. Como conclusión, el Tribunal Constitucional no podrá controlar la constitucionalidad de aquellas normas que previamente hayan sido objeto de la deliberación parlamentaria conforme a la Ponderación.
AbSTRACT

This essay present the fundamental rights competency norms as an approach from what is here called the theory of fundamental rights to articulate the legislative configuration and judicial review. That theory will be analyzed in order to declare that the fundamental parliamentary deliberation and the judicial review are ruled by balancing. Therefore, the reciprocal respect between the Parliament and the Constitutional Court, in this issue, is about competence and balancing. As a conclusion, the Constitutional Court may not control the constitutionality of those laws that have previously been subject to parliamentary deliberation according to the balancing.

* Profesor de Derecho Constitucional de la Facultad de Derecho de la Universidad Mayor. Licenciado en Ciencias Jurídicas y Sociales de la Universidad Diego Portales, Magister en Derecho Constitucional LLM-UC y Alumno becario del Doctorado en Derecho de la Universidad de Los Andes, Chile. Correo electrónico: antonio.leiva@mayor.cl 


\section{Palabras clave}

Derecho constitucional - normas sobre derechos fundamentales - ponderación - control de constitutionalidad - normas competenciales - deliberación parlamentaria.
KEYWORDS

Constitutional Law - human rights regulations - balancing - judicial review - competency norms - parliamentary deliberation.

Recibido el 21 de mayo de 2019 y aprobado el 13 de julio de 2020.

\section{INTRODUCCIÓN}

El gran tema que enfrentamos en el Derecho Constitucional chileno es uno relacionado con la jurisdicción constitucional. Ese asunto puede ser descrito como el de la cuestión sobre el límite entre la acción modeladora del legislador y el control de constitucionalidad de su producción por parte del Tribunal Constitucional.

Este trabajo puede ser sintetizado como un esfuerzo dogmático, inscrito en la teoría de los derechos fundamentales, por ofrecer a los protagonistas del asunto recién descrito -más específicamente, a los operadores de esos ámbitos- una herramienta que permita precaver o dirimir, según sea el caso, las tensiones que provoca la ausencia de criterios genuinamente jurídicos para trazar una línea divisoria entre la tarea iusfundamental del Congreso Nacional y del Tribunal Constitucional. La deferencia razonada, habrá que investigar en otra ocasión los motivos, ha fracasado en esa faena, no vale la pena ocultarlo. Sobre todo -por razones fáciles de intuir-, no ha sido mínimamente persuasiva para radicarse en la cultura jurídica nacional como un medio que suministre por sí mismo decisiones de calidad racional.

Utilizando el método de la dogmática jurídica, este trabajo presenta a la ponderación como un modelo con la suficiente densidad dogmática, bien poblado de fundamentos filosóficos, de técnica normativa, de procedimientos y conceptos jurídicos, para desarrollar la faena en comento. Resumidamente, se sostiene que el trabajo legislativo de fijar límites a los derechos fundamentales mediante normas legales que los restrinjan, debe hacerse satisfaciendo los estándares de la proporcionalidad. Luego de haberse razonado al son de la ponderación en ese escenario, el Tribunal Constitucional sólo podrá corroborar que eso haya ocurrido, debiendo abstenerse de pronunciarse constitucionalmente en contra del raciocinio iusfundamental del Congreso Nacional. En caso contrario, cuando el legislador no haya desplegado ni dejado testimonio de ese esfuerzo argumental mínimo, el Tribunal Constitucional debe aplicar la ponderación para resolver la constitucionalidad de la afectación iusfundamental. 


\section{Presupuestos}

La deliberación parlamentaria se endereza como un quehacer también jurídico, es decir, como un fenómeno propio del Derecho -no sólo político y moral $-^{1}$ por lo que sobre él pesa la naturaleza binaria que se observa en lo jurídico, cual es, la real -o material- de la legalidad y de la eficacia y la ideal -o crítica- de la corrección ${ }^{2}$. Es la dimensión crítica, la central en este trabajo. La corrección se encuentra necesariamente vinculada con la Ponderación, pues sólo es posible advertir que una norma-iusfundamental, en lo que aquí interesa-, es mínimamente justa en la medida que irrogue una afectación proporcionada a las posiciones de derecho fundamental que se yerguen a partir de ella.

En lo que sigue de este apartado, se explicarán algunos tópicos que cumplen simultáneamente dos funciones. Por una parte se trata propiamente de los presupuestos para que una tesis como la que aquí se promueve sea -primero- examinable (falsable) y luego correcta. Y por otra, el desarrollo de estos temas permitirá fijar las bases del sistema dogmático y normativo sobre las que posa la tesis que aquí se promueve.

\section{La Constitución como fuente formal}

El primer presupuesto para una tesis como la que aquí se emprende, es la concepción de Constitución como norma, es decir, en el sentido deóntico del término, una fuente formal, como mejor lo dice Henríquez Viñas ${ }^{3}$, con eficacia directa. Afirmar la Constitución como fuente directa del derecho, importa a un turno tenerla como integrante de la batería de prescripciones que cualquier aplicador debe por fuerza considerar para resolver una cuestión jurídica, y luego ponerla - por efecto de la supremacía constitucional-, presidiendo el sistema de fuentes.

Es forzoso tener en consideración -luego de lo conceptual- el nivel pragmático de este tópico. Con infinito orden, Aldunate ${ }^{4}$ sistematiza los efectos de la reconfiguración normativa de la constitución. En esta ocasión

${ }^{1}$ LeIVA, Antonio, Deliberación Legislativa y Corrección: Un ensayo sobre la legislación iusfundamental como un quehacer regido por normas jurídicas sustantivas, en Revista de Derecho Aplicado LLM UC 2 (2018), p. 6.

${ }^{2}$ La denominación de dimensión ideal y dimensión crítica, pertenecen a BERNAL Pulido, Carlos, La Doble Dimensión del Derecho (Lima, Palestra, 2011), p. 18.

${ }^{3}$ Henríquez Viñas, Miriam, Las Fuentes Formales del Derecho (Santiago, LegalPublishing, 2009), p. 32.

${ }^{4}$ Aldunate Lizana, Eduardo, La Fuerza Normativa de la Constitución y el Sistema de Fuentes del Derecho, en Revista de Derecho de la Pontificia Universidad Católica de Valparaiso 32 (2009), pp. 445-452. 
habrá que detenerse sólo en alguno de ellos. Primeramente, debe destacarse que la eficacia directa de la Constitución puede describirse recurriendo a conceptos intelectuales de raigambre normativa del tipo "verdaderas normas jurídicas", "obligatorias”, que "no constituyen meros programas, idearios o planes" o que "su transgresión debe conducir a la correspondiente sanción" ${ }^{5}$. A lo recién afirmado, debe agregarse otro asunto relacionado en que -felizmente- el profesor Aldunate recuerda. La eficacia directa de la Carta Fundamental, tiene una expresión en punto a la necesariedad -o la falta de ella-, de asistencia de la ley en orden a su aplicación. Citando a Fernández González, Aldunate nos orilla a la conclusión de que en materia iusfundamental tal auxilio legal es innecesario - en sentido técnico-, siendo éste sólo contingente, pues sería requerido sólo respecto de la regulación orgánica ${ }^{6}$.

Pero lo que para los efectos que aquí importa, el cuadro se completa con la descripción del efecto de irradiación. El autor que se viene analizando $^{7}$, señala que el resultado más gravitante del carácter normativo de la Constitución resulta ser que obliga universalmente, sin distinción de la naturaleza de los órganos, entronizando el efecto horizontal de los derechos fundamentales. En un sentido más preciso, describe su incidencia singular de índole iusfundamental en el derecho común, es decir, en las relaciones domésticas, por oposición a la noción previa orientado a la autoridad pública ${ }^{8}$.

Pues bien, sólo de una Constitución -en el sentido iusfundamental de la expresión- con esa morfología normativa, directa y autárquicamente eficaz -que no necesita el auxilio de ninguna otra norma para aplicarse-, encabezando el sistema de fuentes e independiente en punto a sus reglas de aplicación, es posible predicar condiciones adecuadas para el argumento de la corrección. Lo anterior, habida cuenta que la eficacia de las normas -o de la sanción a la ineficacia- y del ordenamiento, conforma uno de los elementos del concepto de Derecho que aquí se consulta?

\section{La argumentación juridica}

La Constitución no ordena jerárquicamente los derechos fundamentales, eso ya se sabe. Por lo tanto, cuando sea el caso habrá que preguntarse

${ }^{5}$ Aldunate, cit. (n. 4), p. 446.

${ }^{6}$ Aldunate, cit. (n. 4), p. 453.

${ }^{7}$ Aldunate, cit. (n. 4), pp. 448-449.

${ }^{8}$ Aldunate Lizana, Eduardo, Derechos Fundamentales (Santiago, LegalPublishig, 2008), pp. 211-212.

${ }^{9}$ LeIva, Antonio, Proporcionalidad y Justicia Constitucional (Santiago, Libromar, 2018), p. 30. 
respecto de cuál de las posiciones construidas a partir de ellos militan mejores razones a su favor para disciplinar una contienda y dirimir esa disputa. Allí la interdicción de la arbitrariedad que pesa sobre los poderes públicos los obliga a dar cuenta de los motivos que animaron la decisión de disipar un conflicto de una forma determinada y a decidir conforma a esa argumentación.

Esa afirmación introduce un tipo de dificultad estructural al derecho, particularmente en el ámbito iusfundamental, cual es que es que resulta ser escasamente posible -en una versión cartesiana de la racionalidadcontar con material deliberativo apto o evidencia incuestionable para dar solución a una cuestión jurídica. En este ámbito, es frecuente hallar preceptos normativos de contenido indeterminado, es decir, que pueden ser especificados en diversas hipótesis distintas y hasta contradictorias entre algunas de ellas. Ello, estrella a los operadores con el dilema sobre la validez de los enunciados en cuya virtud se pretende dirimir una contienda. En tal escenario, la interpretación, esto es, el proceso de fundamentación de una proposición normativa mediante el concurso otra proposición -y así al infinito-, debe ser enjuiciado como pleno de intenciones rectas y esfuerzos sinceros. Sin embargo, al mismo tiempo muestra una vocación de insuficiencia soberana para dotar de validez a la premisa obtenida mediante su concurso. La interpretación, está epistémicamente construida sobre la tesis consistente en que el intérprete encontrará -tarde o temprano- una proposición normativa que ya no debe ser fundamentada, que es válida en términos absolutos. Ese proceso es altamente insatisfactorio en términos del examen de la corrección de la decisión. Producto de la interpretación, lo que se obtendrá - de ser llevada racionalmente- es la fijación del campo semántico de una norma directamente estatuida en la Constitución, esto es, la mera constatación de una proposición lingüística que el intérprete propone pertenecer realizativamente a un enunciado constitucional, del cual obtiene su validez inicial ${ }^{10}$. Sin embargo, la ya mencionada ambigüedad de los términos constitucionales impide afirmar que la mera circunstancia de encontrar una premisa perteneciente semántica y realizativamente a un precepto positivado, baste para adjudicar un caso en su virtud. En efecto, es una experiencia común interpretar un precepto para obtener no sólo una sino -de ordinario- varias premisas que le pertenecen. Allí, la interpretación muestra su insustituible valor para obtener las aseveraciones interpretativas ${ }^{11}$, que también podrían llamarse premisas con filiación en

\footnotetext{
${ }^{10}$ LeIva, cit. (n. 9), pp. 99-102.

${ }^{11}$ Bernal Pulido, Carlos, El Principio de Proporcionalidad y los Derechos Fundamentales (Madrid, Centro de Estudios Políticos y Constitucionales, 2007), p. 120.
} 
los preceptos, al tiempo que exhibe que la selección racional de una de ellas postergando otras, no puede ser el producto de su concurso.

Es por ello, que el proceso de búsqueda del material para resolver un asunto iusfundamental mediante la interpretación debe ser complementado seguidamente por la fijación de exigencias a la actividad de la fundamentación ${ }^{12}$ : esto es la argumentación jurídica.

La interpretación como quehacer deviene insuficiente para unir -por una parte- la proposición de material autoritativo extraído de una norma positivada, cuando ese material no es bastante, y-simultáneamente-dotar de validez definitiva a tal proposición. Interpretar, es decir, el ejercicio de determinar el sentido, pero sobre todo el alcance de una norma jurídica, sólo permite radicar dentro de ese confín la propuesta lingüística necesaria para resolver una contienda. En el mejor de los casos producto de la interpretación se podrá determinar si la propuesta normativa pertenece o no a la norma positiva de la que ella brota. Sin embargo, mirada suficientemente de cerca, no permite - pues excede sus posibilidades técnicas y lógicasatribuirle validez terminal a esa propuesta y mucho menos responder cómo actuar ante la proposición de una hipótesis lingüístico-normativa adversa para ese mismo caso, situación que de ordinario conforma un genuino conflicto jurídico.

Conviene pensar en la argumentación también como un quehacer destinado a obtener la adhesión del auditorio, es decir, de aquellos a quienes se dirige ${ }^{13}$. Es por ello que la adjudicación en un caso determinado por la ausencia de material autoritativo suficiente, sólo puede producirse mediante la argumentación jurídica.

Presuponiendo que las cuestiones prácticas pueden resolverse racionalmente, el remedio para la manifestación de dicha conflictividad-colisiones o afectaciones iusfundamentales- y/o la falta de determinación semántica de las normas iusfundamentales -como ya se dijo suele ocurrir-, no puede ser otro que discernir y motivar racionalmente -con el concurso de justificaciones, demostraciones y análisis evidencial- cuál y bajo qué condiciones un argumento se impone sobre otro. Lo anterior, equivale a distinguir estructuralmente entre el establecimiento de una premisa normativa -mediante la interpretación-y la acción de justificarla, esto es proponer la mejor defensa para postergar coyunturalmente una posición iusfundamental basada en un derecho en favor de otro.

En efecto, el decisor ya no puede apoyarse en una mera autoridad

${ }^{12}$ Alexy, Robert, Teoría de la Argumentación Jurídica (Madrid, Centro de Estudios Políticos y Constitucionales, 2012), p. 177.

${ }^{13}$ Perelman, Chaïm - Olbrfecht-Tyteca, Lucie, Tratado de la Argumentación (Madrid, Gredos, 2017), p. 54. 
formal, habida cuenta que en una sociedad moderna no sólo se exigen decisiones dotadas de autoridad sino que se demandan razones ${ }^{14}$. Para decirlo de otra forma, el poder del juez en particular o del decisor en general reside en la aceptabilidad de sus decisiones ${ }^{15} \mathrm{y}$ no en la posición formal de poder; a través de la justificación crea la credibilidad en la que descansa la confianza que los ciudadanos tienen en él ${ }^{16}$.

Es bien sabido que el cumplimiento de las reglas de argumentación -jurídica, en lo que aquí incumbe- no garantiza la certeza o predictibilidad del resultado. No está diseñada para ello ni es disvaliosa por no lograrlo. La virtud que le es propia, brota de que su concurso impregna de racionalidad su resultado ${ }^{17}$. En este orden de cosas, lo que debe predominar es la obligación de presentar justificaciones de las decisiones como un medio para asegurar con base racional la existencia de la certeza jurídica en una sociedad $^{18}$. Sólo una argumentación jurídica racional y correcta sirve de garantía para hacer primar una posición iusfundamental sobre otra, pues esa primacía es una restricción al mencionado derecho. Lo anterior quiere indicar, que la restricción institucional de un derecho fundamental -eso son las decisiones de la autoridad, no tiene sentido ocultarlo- se legitiman por la racionalidad y la argumentación, pues de lo contrario se trataría del mero ejercicio de la fuerza estatal.

\section{La inconstitucionalidad}

Afirmar la existencia jurídica de normas constitucionales, en el sentido técnico de la expresión, supone predicar de ellas una cierta pertenencia a las disposiciones del ordenamiento jurídico que preside, en lo deseable, cuando se las utiliza para disciplinar un caso determinado, pero también cuando se produce un efecto inconveniente pero previsible e inevitable, como el incumplimiento. A ese incumplimiento genérico de la Constitución se le llamará inconstitucionalidad ${ }^{19}$. Desde una perspectiva interna, se trata -a fin de cuentas- de un enfrentamiento norma-norma, una cuestión sobre la compatibilidad del contenido normativo que se atribuye a la regulación legal con el contenido normativo que se atribuye a la regulación constitucional ${ }^{20}$. Así, cabe pensar la inconstitucionalidad como

${ }^{14}$ Aarnio, Aulis, Lo Racional como Razonable (Lima, Palestra Editores, 2016), p. 32 .

${ }^{15}$ Habermas, Jürgen, Facticidad y Validez (Madrid, Trotta, 2010), pp. 267 y ss.

${ }^{16}$ Aarnio, cit. (n. 8), p. 32.

${ }^{17}$ Alexy, cit. (n. 5), p. 177.

${ }^{18}$ Aarnio, cit. (n. 8), p. 32.

${ }^{19}$ LeIva, cit. (n. 4), p. 39.

${ }^{20}$ Aldunate, cit. (n. 8), p. 187. 
un conflicto normativo ${ }^{21}$, es decir, como la situación que se da cuando dos o más normas son formal o materialmente incompatibles ${ }^{22}$. A esa aproximación, sólo cabría agregar aquí que dicha incompatibilidad -que se denomina antinomia ${ }^{23}$ - se da en el nivel deóntico de cada norma, es decir, entre aquello que está prohibido, permitido o que es obligatorio de acuerdo al precepto normativo de que se trate, y lo que -a su turno- está prohibido, permitido o es obligatorio en la otra. Ello puede producirse -desde la base- habida cuenta de que la ley forma parte del sistema normativo creado por la Constitución, por lo que las relaciones normativas importan un desarrollo conforme a ella.

Bajo este concepto, deben -ineludiblemente- comprenderse también los conflictos de derechos. Se entiende que estos están presentes "cuando el efecto jurídico de la protección iusfundamental alegada por un sujeto (titular del respectivo derecho) es incompatible con el efecto jurídico perseguido por otro sujeto a partir de un alegato de protección iusfundamental" 24 .

Así entendida la colisión de derechos, ella es un conflicto entre posiciones jurídicas erguidas o que brotan en punto a normas. Por ello, el conflicto de derechos es sobre todo un conflicto normativo. Éste tiene la singularidad, y que lo distingue del caso reseñado más arriba, de que puede darse también entre posiciones emanadas todas de la propia Constitución, y no sólo en los casos en que unas emanen de la ley y otras de la Carta Fundamental. En esa situación, lo que aquí se afirma es que en esa clase de casos sólo una posición iusfundamental es constitucional, en el sentido que se viene predicando. Esto es así, debido a que la colisión de derechos entraña necesariamente el dilema de que sólo una de las posiciones en conflicto tiene amparo constitucional, lo que equivale a que sólo una de ellas es deónticamente compatible con la constitución: la precedencia de una posición iusfundamental en contra de otra, fundada en que aquella que prima, es la única que sobrevive el test de constitucionalidad. Es por ello, que el conflicto de derechos debe rotulárselo como inconstitucionalidad iusfundamental.

${ }^{21}$ Huerta, Carla, Conflictos Normativos (México D.F, Universidad Nacional Autónoma de México, 2003), pp. 59 y ss.

${ }^{22}$ Huerta, cit. (n. 21), p. 52.

${ }^{23}$ No importa aquí la tipología de la antinomia que mejor aplica para esta clase de conflicto normativo, es decir, la inconstitucionalidad iusfundamental. Sobre ese asunto, ver Henriquez, Miriam, Los Jueces y la Resolución de Antinomias desde la Perspectiva de las Fuentes del Derecho Constitucional Chileno, en Estudios Constitucionales 1 (2013), pp. 461-463.

${ }^{24}$ Aldunate, cit. (n. 8), p. 269. 


\section{La Teoría de los Derechos Fundamentales}

Jurídicamente los derechos, en cuanto entes morales, no son tangibles. En rigor no lo son siquiera para los ciudadanos; el vínculo entre ellos se resuelve en punto al goce y el ejercicio de esos derechos. Su entidad -usando el término provisionalmente- es inabordable, resultando ser de aquellas cosas que no pueden ser dichas con claridad, las que se deben dejar pasar en silencio ${ }^{25}$. Se trata -en fin-, de aquello que sólo puede ser estudiado y abordado por el derecho mediante el lenguaje que se refiere a él y los actos jurídicos -en la especie legislativos- que recaen sobre ellos. Por lo tanto, al alcance del derecho sólo está el lenguaje referido a los derechos fundamentales -en el dominio de la Filosofía del Derecho-y-seguidamente- la regulación propiamente dicha que recae en ellos ${ }^{26}$, cuestión propia del Derecho Constitucional de los Derechos Fundamentales.

Aquella es la razón por la que una teoría constitucional de los derechos fundamentales no puede sino referirse sólo a las normas iusfundamentales. Sin perjuicio de ello, no se advierte inconveniente en que las nomas sobre derechos fundamentales pueden ser concebidas como la conexión con los derechos fundamentales en la medida que sean una representación, una manifestación de ellos. Sin embargo, nada cambia el hecho que sólo son jurídicamente asequible al derecho constitucional las normas iusfundamentales.

Dicha correlación entre los derechos fundamentales y las normas iusfundamentales se dará en la medida que la regulación iusfundamental satisfaga un requisito elemental, cual es erguirse a partir de una argumentación iusfundamentalmente correcta ${ }^{27}$. Esto ocurrirá, cuando el precepto que brote del proceso deliberativo no afecte desproporcionadamente las posiciones jurídicas del derecho que se regula ni las demás que pueda afectar y que correspondan a otros derechos. Esto es lo mismo, que satisfacer el principio de proporcionalidad.

La afectación desproporcionada de las posiciones de derecho fundamental por las normas restrictivas iusfundamentales, si bien no les confieren tangibilidad -como una clase de perceptibilidad en sí mismos-, permite advertir una manifestación jurídica de ellos. Ella es la presencia implícita de la justicia en toda norma jurídica iusfundamental. Es posible afirmar sa manifestación jurídica de ellos en punto a la contradicción performativa que se advierte en las afectaciones desproporcionadas a las posiciones

25 Wittgenstein, Ludwig, Tractatus Logico-Philosophicus (Barcelona, Gredos, 2017), p. 5.

${ }^{26}$ Lo anterior es sin perjuicio que cualquier norma es también -ciertamente- una expresión lingüística.

${ }^{27}$ AleXY, cit. (n. 12), p. 53. 
iusfundamentales que descansan sobre la idea de derechos fundamentales. Se entenderá por contradicción performativa, la disparidad entre una aserción explícita -la que se observa en el enunciado normativo- y una aserción implícita, donde esta última se acepta como presupuesto necesario al llevar a cabo el acto que contiene la aserción ${ }^{28}$. Es por ello que la Teoría de los Derechos Fundamentales además de aportar explicaciones e hipótesis sobre las normas iusfundamentales es una teoría sobre la validez de dicha regulación.

Estando los derechos fundamentales vinculados al Estado sólo analíticamente, mediante una actividad simbólica de raigambre intelectual al mismo tiempo que colectiva, es decir, regulativamente, las teorías jurídicas sólo pueden versar sobre las normas cuyas prescripciones tocan los derechos fundamentales, sea que los reconozcan, los extiendan, los restrinjan, etc. Esto es lo que se llama intervención iusfundamental ${ }^{29}$. Con tino significativo, Aldunate ${ }^{30}$ le presta atención a que es consustancial al fenómeno de la afectación iusfundamental, un detrimento, esto es, una merma en la cabida de la protección, aunque es perfectamente posible que ello se haga en armonía con el derecho.

Es por ello que el objeto externo de una Teoría de los Derechos Fundamentales, como a la que este trabajo tributa, son las disposiciones de derecho fundamental, o lo que es lo mismo de los enunciados normativos iusfundamentales. La expresión interna de ese objeto, son las normas siempre en el sentido deóntico de la expresión-contenidas en los referidos preceptos. Cuáles son las acepciones que se incluyen en el término normas de derechos fundamentales, serán revisadas seguidamente.

Lo que debe ser dicho ahora es que la delimitación del objeto de una teoría de los derechos fundamentales como la recién descrita, está determinantemente relacionada con la teoría de la corrección, es decir, con aquella concepción del derecho en su dimensión crítica. Para que sea siquiera posible exigir que una norma albergue una pretensión de esta clase para ser válida, debe haber una acción humana -o, como en este caso, el producto de una o varias acciones- que pueda o ajustarse a dicho estándar o incumplirlo. Aquí, debe haber una conducta que haya sido concebida con la pretensión de ser mínimamente justa. Las cosas o los hechos no son susceptibles de corrección ${ }^{31}$, ni pueden ser base de una teoría como la que aquí se consulta.

\footnotetext{
${ }^{28}$ AleXY, Robert, El Concepto y la Validez del Derecho (Barcelona, Gedisa, 1994), p. 44.

${ }^{29}$ Bernal, cit. (n. 11), p. 122.

${ }^{30}$ Aldunate, cit. (n. 8), p. 226.

${ }^{31}$ Wittgenstein, cit. (n. 17), p. 7.
} 
Pero la afirmación de una Teoría de los Derechos Fundamentales como presupuesto de la tesis que se presenta en este trabajo tiene una segunda connotación.

Como se podrá observar de lo presentado hasta ahora, pero sobre todo de lo que sigue, el término Teoría de los Derechos Fundamentales no está usado en alusión a la obra de Robert Alexy, sino ya con una cierta independencia epistemológica, al borde de la diferencia disciplinar. Sostener esta diferencia, importa recorrer una ruta en alguna medida paralela a la obra de Alexy, a quien se le debe el invaluable origen de esta formidable corriente de pensamiento iusfundamental, con la que se comparten ciertas explicaciones e hipótesis, pero con la que al mismo tiempo se observan divergencias cuya entidad y envergadura resulta imposibles exagerar.

Los elementos que hoy se observan irreductibles en la Teoría de los Derechos Fundamentales, en un estado tal que de ello puede predicarse que de faltar se estaría ante una teoría diferente, son -al menos- la teoría del caso especial ${ }^{32}$, la teoría de la corrección ${ }^{33}$, la teoría de los principios $^{34}$ $\mathrm{y}$-desde luego y por añadidura- la teoría de la ponderación ${ }^{35}$. Sin embargo, ya es posible ver disensos de palpable anchura en punto al contenido de alguno de ellos. Por nombrar algunos, Bernal Pulido ${ }^{36}$ sostiene que la máxima realización posible de un principio no sólo depende de las condiciones fácticas y jurídicas, como originalmente y hasta ahora sostiene Alexy, sino que también epistemológicas, para incorporar una garantía del respeto por la competencia del margen de acción del Parlamento. Por otra parte, Carsten Bäcker ${ }^{37}$ sostiene que la distinción correcta entre las reglas y los principios, no es -como sostiene Alexy- la optimizabilidad de estos últimos sino a su derrotabilidad. Finalmente, puede nombrarse el caso de Aharon Barak ${ }^{38}$, quien sostiene que el producto del proceso de adscripción que está a la base de la aplicación del procedimiento de ponderación es de rango infraconstitucional, mientras Alexy sostiene -con mejores razonesque una norma adscripta de derecho fundamental goza de validez prima

${ }^{32}$ Alexy, cit. (n. 20) pp. 206 y ss.

${ }^{33}$ AleXY, cit. (n. 20), pp. 81 y ss.

${ }^{34}$ Alexy, cit. (n. 12), pp. 63 y ss.

${ }^{35}$ Alexy, cit. (n. 12), p. 92.

${ }^{36}$ Bernal Pulido, Carlos, Estudio Introductorio a la Teoría de los Derechos Fundamentales de Robert Alexy (Madrid, Centro de Estudios Públicos y Constitucionales, 2012), p. LIII.

${ }^{37}$ BÄCKER, Carsten, Reglas, Principios y Derrotabilidad, en DOXA. 37 (2014), p. $31-44$.

${ }^{38}$ BaraK, Aharon, Proporcionalidad (Lima, Palestra Editores, 2017), p. 64. 
facie, pues lo obtiene de la pertenencia al campo semántico de la norma directamente estatuida en la propia Constitución.

\section{LA LEGISLACIÓN Y LAS NORMAS DE DERECHO FUNDAMENTAL}

\section{Las normas de derecho fundamental}

Las normas de derecho fundamental, están relacionadas -desde luego, como toda norma- con las modalidades deónticas, pero también con las disposiciones de derecho fundamental contenidas en la Constitución.

A esta explicación, vale la pena agregar que bajo esta denominación no sólo debe quedar comprendido el enunciado iusfundamental del texto constitucional -en el sentido protectivo ${ }^{39}$ de la expresión-sino también los preceptos relativos a sus límites y posibilidades de regulación ${ }^{40}$, también llamado ámbito normativo iusfundamental ${ }^{41}$.

En relación con las disposiciones de derecho fundamental, las normas de derecho fundamental deben entenderse como aquellas directamente expresadas por los enunciados normativos ${ }^{42}$. Dicho de otra forma, lo que singulariza a estas normas de derecho son los significados prescriptivos de las disposiciones de derecho fundamental ${ }^{43}$. Debe agregarse que los referidos significados prescriptivos se expresan deónticamente ${ }^{44}$. En suma, en la norma de derecho fundamental se plasma lo que está iusfundamentalmente ordenado, prohibido o permitido.

\section{Las normas directamente establecidas}

Las normas directamente establecidas en la Constitución presentan -de ordinario- un alto grado de abstracción y generalidad, mientras los problemas en la realidad desbordan por mucho y con poco esfuerzo los linderos del texto normativo ${ }^{45}$. Por ello, atribuir únicamente a normas directamente positivadas la virtud de resolver las cuestiones jurídicas iusfundamentales, supone sobrestimar las posibilidades jurídicas reales de ellas al mismo tiempo que pasar por alto la tarea que impone la intensa indeterminación que presentan.

Por varias razones -algunas de las cuales se verán a continuación-, las normas directamente estatuidas no bastan para resolver jurídicamente

\footnotetext{
${ }^{39}$ Aldunate, cit. (n. 8), p. 141.

${ }^{40}$ Aldunate, cit. (n. 8), p. 133.

${ }^{41}$ Aldunate, cit. (n. 8), p. 141.

${ }^{42}$ Alexy, cit. (n. 12), p. 48.

${ }^{43}$ BeRNAL, cit. (n. 21), p. 83.

${ }^{44}$ LeIVA, cit. (n. 4), p. 68.

${ }^{45}$ Bernal, cit. (n. 21), p. 116.
} 
un conflicto o un caso de derechos fundamentales, sea por la ya anotada vaguedad del lenguaje jurídico o porque la generalidad de dichas normas demanda una mayor delimitación deóntica para ser especificadas y de ese modo subsumidas. Es por ello que, junto con las normas directamente positivadas en la Constitución, se encuentran las normas adscriptas de derecho fundamental, las que -bajo ciertas condiciones- están igualmente dotadas de validez definitiva.

\section{Las normas adscriptas de derecho fundamental}

Las normas iusfundamentales indirectamente constitucionales, son las normas adscritas de derecho fundamental. Ellas son enunciados normativos que especifican las normas directamente estatuidas, encontrándose lógica y semánticamente inscritas y/o adheridas a ellas. Se construyen intelectualmente a partir de las mismas, siempre que para su adscripción sea posible una fundamentación iusfundamentalmente correcta ${ }^{46}$, es decir, una argumentación que cumpla el test de proporcionalidad o ponderación, esto es que satisfaga la referida pretensión de corrección.

El uso de la expresión "construcción intelectual" importa afirmar una propuesta de expresión normativa a partir de un proceso inicialmente interpretativo. Ello debido a que las normas adscriptas - para ser consideradas así- forman parte del ámbito semántico de la norma directamente estatuida. De esta manera aseverar esa vinculación supone proponer que la norma adscripta pertenece a una norma directamente estatuida. Sin embargo, el proceso de adscripción no se agota en el nivel interpretativo, sino que debe ser completado racional e institucionalmente.

Aunque la interpretación juega un papel insustituible, el proceso genuinamente adscriptivo es de naturaleza argumental, es decir, un quehacer intelectual orientado a la obtención de adhesión de la institución a la que está dirigida ${ }^{47}$. Lo que aquí ocurre es que para obtener el material autoritativo necesario para la subsunción, -en primer lugar- efectivamente se hace necesaria la proposición de un determinado enunciado normativo vinculado semántica y lógicamente con la norma directamente estatuida. Esto ocurrirá mediante la interpretación. La cuestión es que producto de la interpretación, normalmente se obtendrán no sólo uno sino varios enunciados que se hallan lógica y semánticamente enlazados a la norma directamente estatuida. Todos esos enunciados, ciertamente son especificaciones de la norma de la que germinan. Sin embargo, para dotar insti-

\footnotetext{
${ }^{46}$ Alexy, cit. (n. 12), p. 53.

${ }^{47}$ Perelman - Olbrecht-Tyteca, cit (n. 13), p. 54.
} 
tucionalmente de validez definitiva a sólo uno de ellos, es imprescindible luego una argumentación iusfundamentalmente correcta.

Aquí se afirma que es mediante el proceso de ponderación, que se demuestra cuál de los enunciados interpretativamente obtenidos, es el que tiene a su favor las mejores razones fácticas, jurídicas y epistémicas. Es así que resulta posible afirmar definitivamente -ya no sólo prima facie- que esa norma adscrita es compatible con la norma directamente estatuida.

Respecto de la validez que se advierte en las normas adscriptas interpretativamente obtenidas, ya se mencionó que carecen de validez definitiva. Las normas que nos ocupan están dotadas de una validez prima facie, la que emana de la Constitución, debido a que forman parte del campo semántico y/o normativo de las disposiciones iusfundamentales allí positivadas $^{48}$. El carácter prima facie de una norma adscrita expresa que ella tendrá validez definitiva, a menos que exista una razón de mayor peso que la que le otorgue validez definitiva a la norma contraria ${ }^{49}$, una vez que ello sea así sancionado institucionalmente.

Usando el mismo ejemplo que en otra ocasión ${ }^{50}$, piénsese en el inciso segundo del número 2 del artículo 19 de la Constitución Política de la República. Allí se encuentra una norma directamente estatuida que reza: $[\mathrm{N}] \mathrm{i}$ la ley ni autoridad alguna podrán establecer diferencias arbitrarias. A esta norma es posible adscribirle una propuesta normativa cuyo contenido sea el siguiente: está prohibido constitucionalmente que los abogados sean obligados a defender gratuitamente a las personas. Como se advierte, el trayecto entre ambos preceptos se recorre interpretando, es decir, identificando semántica y lógicamente un enunciado que se contiene en la norma directamente estatuida. Eso es lo que significa especificar un cierto enunciado normativo. Este proceso será genuinamente interpretativo -y no subrepticiamente creativo- en la medida que el enunciado propuesto esté efectivamente vinculado lógica y semánticamente con la norma directamente estatuida en la Constitución ${ }^{51}$. De ello depende que la norma adscripta goce de validez prima facie. Que en definitiva tal norma termine

${ }^{48}$ Bernal, cit. (n. 11), p. 119.

${ }^{49}$ BerNAL, cit. (n. 11), p. 645.

${ }^{50}$ LeIVA, cit. (n. 9), p. 71.

${ }^{51}$ Esta interpretación puede generarse no sólo al son de los cánones tradicionales de interpretación, con preeminencia de la regla semántica y la regla histórica (AlEXY, cit. (n. 28), p. 239), sino que conforme a la producción iusfundamental institucional previa, como las posiciones iusfundamentales reconocidas en otras normas iusfundamentales, en el precedente del Tribunal Constitucional. Es indiscutible la pertinencia de acceder a la doctrina como fuente de normas adscritas, habida cuenta de la pertenencia sistémica a un mismo ordenamiento y que ella suele nutrir a los tribunales y/o a la administración, pero tampoco está en discusión que el producto 
perteneciendo a la norma directamente estatuida -en el sentido que logre tener validez definitiva-, ya no depende del proceso interpretativo sino de la ponderación como argumentación -iusfundamentalmente correcta-, pero sobre todo del acto institucional que lo sancione de esa manera.

Pues bien, estas normas que argumentativamente se adhieren o inscriben en las normas directamente estatuidas, se adhieren o inscriben a ellas con una pretensión de validez -como se dijo- prima facie o inicial, pero siempre orientada a que sobrevenga en definitiva. La validez prima facie de las normas adscriptas deviene en definitiva por dos vías: la concreción o la actualización ${ }^{52}$.

En la concreción de una norma adscripta como el acto jurídico mediante el cual el Tribunal Constitucional asevera -habría que agregar argumentativamente- que una norma adscripta tiene validez definitiva dentro del ámbito de indeterminación de una disposición de derecho fundamentals3. Este acto institucional es una afirmación sobre la existencia de una norma de derecho fundamental ${ }^{54}$.

El proceso que se viene describiendo cuando se desarrolla en sede parlamentaria se denominará actualización ${ }^{55}$. Para preservar la naturaleza de este quehacer, es imprescindible tener presente que las regulaciones de nivel infraconstitucional son válidas en el ámbito que la Constitución reserva a la ley, desplegándose para asegurar y posibilitar el ejercicio de los derechos ${ }^{56}$, en el sentido protectivo de la expresión.

En las zonas de indeterminación semánticas de las normas directamente estatuidas, la Constitución ha investido al Parlamento de varias y muy importantes competencias de intervención en los derechos fundamentales sobre todo la facultad legislativa de imponer-crear-normas de contenido iusfundamental, incluidas la intervención legislativa en un derecho fundamental. En este rubro, el Parlamento pasa de ser un articulador de los intereses sociales que yacen en el fondo de la decisión política a transformarse en una fuente directa de derechos fundamentales ${ }^{57}$, mediante el ejercicio

de la labor iusfundamental institucional se presenta con razones de mayor peso en esta materia.

${ }^{52}$ Bernal, cit. (n. 11), p. 120.

${ }^{53}$ Bernal, cit. (n. 11), p. 120.

${ }^{54}$ AleXY, cit. (n. 12), p. 52.

${ }^{55} \mathrm{El}$ uso de la expresión actualización para identificar el proceso de dotación de validez definitiva de una norma adscrita en sede parlamentaria, se extiende con esa misma denominación al proceso que se realiza en los tratados internacionales sobre derechos humanos, a los reglamentos y demás actos administrativos y a las decisiones judiciales (BERNAL, cit. (n. 11), p. 121).

${ }^{56}$ Aldunate, cit. (n. 8), p. 186.

${ }^{57}$ Bernal, cit. (n. 11), p. 122. 
de potestades normativas, esto es, actuando investido de la capacidad de tomar decisiones que cambian lo que una persona debe o no debe hacer, o es o no capaz de hacer, dentro del marco del ordenamiento jurídico ${ }^{58}$.

Habría que agregar que, si bien ambas son vías institucionales, queriendo significar con ello que tal proceso demanda bis a bis una sanción por parte de una autoridad estatal competente, no es menos cierto que cualquier interviniente en la deliberación puede proponer una norma adscripta. Lo que ocurre es que sólo los órganos dotados de autoridad por el ordenamiento para afinar esos procesos, mediante los procedimientos e instrumentos positivados, pueden dotar de validez definitiva a esas propuestas.

Para explicar funcionalmente este proceso, deben diferenciarse dos clases de normas adscritas: las de adscripción posible y las de adscripción necesaria ${ }^{59}$. Las primeras tienen su espacio en la mencionada zona de indeterminación semántica de las normas directamente estatuidas, donde la Constitución deja abierto un espacio de acción denominado libertad de configuración legislativa, para escoger -entre otras cosas- la estrategia de intervención en el derecho fundamental que considere más conveniente ${ }^{60}$, donde esto último refiere al modelamiento regulativo iusfundamental de acuerdo a consensos técnico-políticos mayoritarios. La actualización hecha de este modo, suma contenido semántico a la regulación iusfundamental directamente estatuida, de manera tal que -salvo para el Parlamento- la infracción de la norma de adscripción posible deviene en una vulneración administrativa o judicial del derecho fundamental.

El Parlamento, no goza de tal competencia -ni ningún otro órgano que actualice normas adscritas- respecto de las normas de adscripción necesaria. Esta clase de adscripción se observa en el espacio constitucional saturado semánticamente por sus enunciados normativos, donde ella ha reservado para sí la regulación iusfundamental, razón por la cual las posibilidades jurídicas de esta actualización se reducen a la plena compatibilidad deóntica con dicha regulación constitucional, o - de lo contrario- se producirá o la invalidez -cuando la saturación semántica es de naturaleza formal- o la inconstitucionalidad -si ella es sustancial-.

Se verá que esta distinción entre ambas adscripciones tiene su correlato en la distinción seguramente más importante para el derecho constitucional iusfundamental: la clasificación de las normas sobre derechos fundamentales en reglas o principios $^{61}$.

\footnotetext{
${ }^{58}$ MacCormick, Neil, Instituciones del Derecho (Madrid, Marcial Pons, 2011),

${ }^{59}$ BERNAL, cit. (n. 11), p. 122-123.

${ }^{60}$ Bernal, cit. (n. 11), p. 123.

${ }^{61}$ AleXY, cit. (n. 12), p. 63. Para este autor la distinción entre reglas y principios
} p. 198. 


\section{Las reglas y los principios}

Explicar la diferencia entre los principios y las reglas no tiene sólo un valor meramente enciclopédico o dogmático, sino que -como se veráexiste una relación muy peculiar entre los principios y la Ponderación.

La distinción entre las reglas y los principios es una distinción entre dos tipos de normas, pues ambos dicen lo que debe ser, es decir, ambos se formulan con la ayuda de las expresiones deónticas básicas del mandato, la permisión y la prohibición ${ }^{62}$. En Alexy, la tesis correcta para diferenciar los principios de las reglas ${ }^{63}$ es la que entiende que la diferencia entre ellos es cualitativa. Por una parte, los principios son normas que ordenan que algo se realice -fáctica y jurídicamente ${ }^{64}$ - en la medida de sus posibilidades, esto es, que su cumplimiento puede darse y así medirse en magnitudes; un principio puede estar cumplido intensamente -como cuando un grupo importante de hipótesis de aplicación quedan satisfechas permaneciendo otras insatisfechas-o menos intensamente. Por eso Alexy también llama a estas normas iusfundamentales mandatos de optimización. Aquí es donde se encuentran las normas de adscripción posible.

Si bien no forma parte de repertorio específico de materias que serán tratadas, deben decirse algunas cuestiones mínimas sobre los componentes del test de proporcionalidad. Lo anterior, debido a que sólo así resulta posible comprender lo que significa en la Teoría de los Derechos Fundamen-

es la más importante distinción teórica y estructural en materia iusfundamental, por lo que se constituye en el pilar esencial de la teoría de los derechos fundamentales. Sin esta distinción -sostiene Alexy-, no puede existir una teoría adecuada de los límites, ni una teoría satisfactoria de la colisión y tampoco una teoría suficiente acerca del papel que juegan los derechos fundamentales en el sistema jurídico. Con su ayuda, es posible hacer más transparentes problemas tales como el efecto respecto de terceros y la división de competencia entre el Tribunal Constitucional y el Parlamento.

${ }^{62}$ Alexy, cit. (n. 12), p. 65.

${ }^{63}$ Sobre otros criterios de distinción entre reglas y principios: DwORKIN, Ronald, Los Derechos en Serio (Barcelona, Ariel, 2012), pp. 72-80; BäCKER, cit. (n. 28), pp. 31-44.

${ }^{64}$ Como se explicará seguidamente, las posibilidades materiales o meramente fácticas de la realización de los principios depende o están expresadas -si se quiere-, en los subprincipios de idoneidad y necesidad, mientras que las posibilidades jurídicas lo están del subprincipio de proporcionalidad en sentido estricto. Respeto de esto último, cuando Alexy usa la expresión jurídicamente posible, se refiere a lo que puede realizarse teniendo a la vista lo que es permitido por el principio contrario, es decir, por el principio cuya realización se vería impedida por la materialización del primero. Piénsese en un binomio de normal conflicto como libertar de expresión-derecho a la honra. Lo que es jurídicamente posible de desarrollar en ejercicio de la libertad de expresión está limitado por aquella dimensión del derecho a la honra que no esté prima facie protegido. 
tales la expresión "posibilidades fácticas y jurídicas». La proporcionalidad concebida como test, está compuesta por tres subprincipios, a saber, el de idoneidad, el de necesidad y el de ponderación. Como lo explica Bernal Pulido ${ }^{65}$, en virtud del subprincipio de idoneidad toda intervención en los derechos fundamentales debe ser adecuada para contribuir a la obtención de un fin constitucionalmente legítimo. Como lo describe Díaz García ${ }^{66}$, la medida que se ausculta debe presentar idoneidad teleológica e idoneidad técnica. Además, la medida en examen debe ser necesaria, y lo será en la medida que la restricción establecida en la ley, al compararla con otra tan adecuada técnicamente como ella, afecte menos el derecho restringido ${ }^{67}$. Finalmente, la medida cuya constitucionalidad se controla debe satisfacer el test de proporcionalidad en sentido estricto o ponderación, es decir-como señala $B_{a r a k}{ }^{68}-$, debe existir una relación adecuada, esto es proporcional en el sentido estricto del término, entre los beneficios -aunque es más correcto decir satisfacción- que se obtienen del cumplimiento del fin y vulneración -aunque es más exacto usar la expresión afectación-causada al derecho fundamental con la obtención de tal fin. Como lo describe Bernal Pulido $^{69}$ las ventajas que se consiguen con la intervención en él derecho fundamental por la medida legal, deben compensar -aunque sería más apropiado decir justificar- los sacrificios que ella irroga a su titular. Pues bien, cuando se señala que los principios se realizan en la medida de sus posibilidades fácticas, lo que se designa es la satisfacción de los criterios de idoneidad y necesidad de la proporcionalidad, mientras que las posibilidades jurídicas dependen de la observancia del subprincipio de ponderación.

A las posibilidades jurídicas y fácticas de los principios para su realización, debe agregarse las condiciones epistémicas ${ }^{70}$, es decir, lo que es posible teniendo en consideración los fundamentos, procedimientos y métodos para -en este caso- la actualización de una norma iusfundamental, con el objeto de proteger los márgenes de configuración del legislador y de acción de la justicia ordinaria.

Mientras tanto, las reglas son normas que -podría decirse- tienen una

${ }^{65}$ Bernal, cit. (n. 11), p. 693.

${ }^{66}$ Díaz, Iván, La Aplicación del Principio de Proporcionalidad en Orden a Juzgar sobre la Licitud o Ilicitud de una Restricción a Derechos Fundamentales, en Revista de Derecho de la Pontificia Universidad Católica de Valparaiso 36 (2011), p. 175.

${ }^{67}$ Clérico, Laura, Examen de Proporcionalidad en el Derecho Constitucional (Buenos Aires, Ediciones Facultad de Derecho de la Universidad de Buenos Aires, 2009), p. 114.

${ }^{68}$ BARAK, cit. (n. 38), 375.

${ }^{69}$ Bernal, cit. (n. 11), p. 764.

${ }^{70}$ Bernal, cit. (n. 37), p. LIII. 
estructura binaria, esto es sólo pueden ser cumplidas o incumplidas ${ }^{71}$ del todo, conteniendo mandatos definitivos de validez -en contraposición a los mandatos de optimización-. Es respecto de las reglas que se aplica lo dicho de las normas de adscripción necesaria.

Lo que explica internamente que una norma iusfundamental sea un principio o una regla, es que mirada como un todo contenga o no una pluralidad de hipótesis que den por satisfecha la modalidad deóntica que contiene. Usando un ejemplo anterior, el precepto que reza ni la ley ni autoridad alguna podrán establecer diferencias arbitrarias, es un principio debido que una pluralidad de enunciados normativos pueden serle adscritos, satisfaciendo la prohibición que prescribe. Entre esa pluralidad de enunciados se encuentra las que reza está prohibido constitucionalmente que los abogados sean obligados a defender gratuitamente a personas con privilegio de pobreza, la que debe ser reconocida como una regla pues -a diferencia de la anterior- no tiene otras hipótesis que se le puedan adscribir, por lo que sólo se la puede cumplir o infringir.

Es importante recordar que la Teoría de los Derechos Fundamentales en general y la proporcionalidad en particular, no son -como ya se explicóteorías ontológicas sobre los derechos fundamentales sino sobre las normas iusfundamentales establecidos en la Constitución. Dicho de otra forma, la teoría que nos ocupa no afirma que los derechos fundamentales sean mandatos de optimización. Lo que afirma es -primero- que las normas iusfundamentales cuando no son reglas, es decir, mandatos definitivos, se comportan o pueden ser descritos como mandatos de optimización. Más específicamente, las normas iusfundamentales establecidas en la Constitución serán principios, siempre que sus prescripciones admitan diversas hipótesis deónticas de distinta intensidad, de manera que ejecutando cualquiera de ellas -desde las más intensas a las menos- la norma se ve cumplida.

Esto no significa que sea indiferente cuál de todas esas propuestas interpretativas termine siendo sancionada institucionalmente. No. De todas esas, sólo es correcto -en el sentido que aquí se consulta- optar por aquella hipótesis que sea -a falta de un mejor término- la mejor de todas, en sentido fáctico, jurídico y epistémico. Que una norma iusfundamental presente la naturaleza de principio, no significa que cualquiera de las hipótesis que se le pueden adscribir prima facie se elegible, de manera que con cualquiera se dé por satisfecha la ponderación. El carácter de principio de una norma iusfundamental, es un asunto de otra índole.

Que ciertos enunciados directamente establecidos en la Constitución se comporten como mandatos de optimización, significa que ante la

${ }^{71}$ AleXY, cit. (n. 12), p. 87. 
pluralidad de hipótesis deónticas que el precepto constitucional admite, habrá que optar por aquella que sea realizable en la mayor medida posible de acuerdo a los límites fácticos, jurídicos y epistémicos.

Desde una mirada externa, que ese espacio de apertura semántica y normativa se dé o no, no depende de ningún método de aplicación, tampoco de la ponderación, sino de una cuestión de hecho: la forma exacta y singular en que se hayan positivado los preceptos sobre derechos fundamentales.

Pero la cuestión central de este apartado, es que a la base de la Teoría de los Derechos Fundamentales se encuentra la teoría de los principios. La vinculación entre ambos es una afirmación analítica sobre la morfología y funcionalidad de las normas iusfundamentales. Ella consiste en que el ordenamiento iusfundamental -primero- está -que es distinto, de "es bueno que esté» - compuesto de dos clases de normas, o reglas o principios, y -luego-, la descripción de éstos últimos como mandatos que son objetos de optimización. Por ello, es más acertado describir dicha vinculación como una concepción y no como un concepto. La diferencia entre ambos es de envergadura. La concepción se yergue como una conclusión, es decir, como una especificación. Mientras un concepto se afirma como una verdad auto-evidente. Mientras una concepción brota de la evidencia y tiene una fuerte conexión con lo jurídico, el concepto surge de las ideas y tiene un componente esencialmente político y/o filosófico ${ }^{72}$.

\section{Las posiciones de derecho fundamental}

Las posiciones de derecho fundamental o los derechos fundamentales en sentido estricto, son relaciones jurídicas entre individuos o entre los individuos y el Estado ${ }^{73}$. Esta noción centra su atención en el objeto del derecho fundamental, es decir, en una o más acciones u omisiones que un titular puede exigir de otro individuo o del Estado y de su correlato, cual es, lo que dicho sujeto y/o tal Estado se encuentran obligados. Lo que se advierte en la formulación de la noción de posición de derecho fundamental y en el ejemplo anterior, es que en ella siempre estará presente una estructura denominada triádica ${ }^{74}$, compuesta por el sujeto activo -titular del derecho-, el objeto del derecho -la acción u omisión- y un sujeto pasivo o destinatario -aquel que debe realizar la acción o que está constreñido por una prohibición-.

En el ejemplo ya utilizado, el sujeto activo es el abogado que se encuentra en posibilidad de ser designado en el turno de defensa gratuita, el

\footnotetext{
${ }^{72}$ Atria, Fernando, La Forma del Derecho (Madrid, Marcial Pons, 2016), p. 275.

${ }^{73}$ Bernal, cit. (n. 21), p. 85.

${ }^{74} V$. gr., AleXY, cit. (n. 12), p. 163 y Bernal, cit. (n. 21), p. 86.
} 
objeto es la prohibición de ser designado y el sujeto pasivo es el juez que en los hechos puede hacer la designación.

\section{El CONTROL DE CONSTITUCIONALIDAD EN LA TEORÍA DE LOS DERECHOS} FUNDAMENTALES

En el apartado anterior, se revisaron las cuestiones centrales sobre la estructura de los derechos fundamentales, en el entendido que dicha tarea es relevante para comprender la primera de las funciones del principio de proporcionalidad: estructurar la fundamentación de la dotación de contenido de los derechos fundamentales.

Pues bien, en esta sección lo que se hará será realizar una tarea homóloga pero ahora respecto a la estructura general del control de constitucionalidad desde la perspectiva propia de la teoría que nos ocupa, con la finalidad de presentar la segunda de las funciones de la ponderación, cual es la fundamentación por el Tribunal Constitucional del contenido de los derechos fundamentales en las decisiones de control de constitucionalidad de las leyes.

Para referirse a la Estructura del Control de Constitucionalidad de la ley, lo primero es hablar del control de constitucionalidad. Como su propio nombre lo indica, el control de constitucionalidad de las leyes designa un procedimiento orientado a determinar si una norma de rango legal resulta jurídicamente compatible -en el sentido deóntico de la expresión- con la Constitución ${ }^{75}$. Dicho más específicamente, tal procedimiento tiene el propósito de elucidar si la norma contenida en un precepto que de acuerdo al ordenamiento positivo tiene rango legal es deónticamente compatible con la norma contenida en un precepto que forme parte de la Constitución. Aquí la dimensión que debe atenderse es la referida sólo a los derechos fundamentales, que se centra en la inconstitucionalidad como fenómeno. En ese orden de cosas, se dirá que la vulneración de un derecho fundamental es un caso especial de inconstitucionalidad ${ }^{76}$. En ella se comprende la intervención legal incompatible con el contenido normativo de la norma iusfundamental, es decir, en el nivel deóntico.

Las discusiones jurídicas se refieren a lo que debe o no debe hacerse, a lo que puede o no ser omitido, pero no ilimitadamente-como las argumentaciones prácticas generales- sino que bajo los parámetros de las normas de derechos fundamentales. Sin embargo, como ya se ha mencionado, tener a la vista las disposiciones jurídicas directamente estatuidas no supone

\footnotetext{
${ }^{75}$ LeIVA, cit. (n. 4), p. 80.

${ }^{76}$ Bernal, cit. (n. 11), p. 90.
} 
conocer el contenido de dichas competencias y derechos fundamentales con la precisión necesaria, pues la indeterminación de los enunciados hace que no sirvan -normalmente- sin más para resolver una contienda iusfundamental, esto es, que permitan la subsunción. Por el contrario, las más de las veces la decisión jurídica no se sigue lógica y directamente de los enunciados jurídicos positivados que se presuponen vigentes ${ }^{77}$.

Pero esta labor, no sólo dice relación con aspectos materiales o procedimentales como la argumentación, sino con cuestiones sustantivas. Las sentencias del Tribunal Constitucional en cuanto acto jurisdiccional, no valen simplemente como un acto de autoridad. Cosa distinta, se pretenden a sí mismas como decisiones correctas, procuran ser reconocidas en la práctica constitucional como tales y pretenden ser consideradas por sí mismas como decisiones fundamentadas ${ }^{78}$. Esto es lo que-de una manera genérica- entraña la pretensión de corrección. Se advierten buenas razones para afirmar lo anterior, como por ejemplo si se sostiene, que la función de los jueces -incluyendo a los constitucionales- no es sólo fijar el derecho aplicable al caso, es decir, una tarea ligada a las fuentes, sino -en lo que nos ocupa- también esclarecer la justificación de las órdenes coercitivas particulares $^{79}$. Sostener lo contrario, significaría tomar a las sentencias simplemente como la manifestación de un poder público, existiendo como tal y cumpliendo su función aun cuando no sea defendible argumentalmente y/o sea injusta. Esto supondría una contradicción performativa, en el sentido ya anotado.

Las decisiones del Tribunal Constitucional, para tenerlas por fundamentadas, habrán de encontrarse justificadas interna y externamente ${ }^{80}$. En la justificación interna se verificará si la decisión se sigue lógicamente de las premisas que se aducen como fundamentación, es decir, tanto a los antecedentes de hecho como los de derecho. Mientras tanto, en la justificación externa se corrobora la validez -es decir, la corrección- de las premisas internas. Dicho de otra forma, en la justificación externa se discuten las fuentes de la decisión, en tanto que en la justificación interna se determinará la concordancia entre la decisión y dichas fuentes. Este proceso es el trayecto desde las normas más generales a las más específicas, hasta llegar al fallo.

Es por ello que -conforme a lo antedicho-, el tema más prominente de la argumentación interna en el control de constitucionalidad iusfunda-

${ }^{77}$ V. gr., AleXY, cit. (n. 12), p. 23.

${ }^{78}$ Habermas, cit. (n. 15), p. 268.

${ }^{79}$ Soper, Philip, Una Teoría del Derecho (Madrid, Centro de Estudios Constitucionales, 1993), p. 175.

${ }^{80}$ AleXY, cit. (n. 23), p. 214. 
mental, es elucidar el contenido del derecho fundamental y el contenido de la norma legal de contenido iusfundamental ${ }^{81}$.

Es en esta etapa del proceso en que se detectará la inconstitucionalidad en sentido estricto, a saber, el conflicto normativo de orden deóntico entre la norma iusfundamental directamente estatuida en la Constitución y la norma legal que la afecta, donde puede romperse la presunción de constitucionalidad de la ley. En definitiva, es aquí donde se afinarán las normas necesarias para resolver los conflictos jurídicos, pasando de dotarlas de validez prima facie a entregarles validez definitiva. Es en esta etapa de la argumentación en donde se evalúa la corrección de las normas, en el sentido que se viene esgrimiendo; aquí la sentencia pasa de ser un mero acto de autoridad a convertirse en una manifestación de la justicia iusfundamental.

\section{LA TEORÍA DE LOS DERECHOS FUNDAMENTALES COMO ARTICULADORA}

\section{COMPETENCIAL}

La Teoría de los Derechos Fundamentales, puede también ser presentada como una propuesta de articulación de competencias jurídicas entre el Parlamento y el Tribunal Constitucional, en materia iusfundamental. Ya se dijo que esta teoría tiene como objeto las normas constitucionales sobre derechos fundamentales, y no alcanza a las tesis generales (teórico-jurídicas) sobre los derechos fundamentales ${ }^{82}$. Es decir, se trata de una teoría relativa a la forma regulativa positivadas en que los derechos fundamentales están consagrados en la Constitución, y no una teoría sobre cómo los derechos fundamentales deberían estar regulados en ella. Debe recordarse, que aquí no se sostiene que los derechos fundamentales sean tales o cuales entes. Por el contrario, en su sentido ontológico, filosófico o político, nada de se dice de ellos. Lo que aquí se afirma, es que aquello que pertenece a la teoría de los derechos fundamentales, son sólo y simplemente las normas -en sus diversas expresiones- positivas en la Constitución que versen sobre derechos fundamentales.

\section{El Tribunal Constitucional y el Poder Legislativo}

La Constitución no sólo vale en contra de la legislación, sino sobre todo mediante ella ${ }^{83}$; es en sede parlamentaria donde también se concretan las normas iusfundamentales y los demás enunciados constitucionales.

En efecto, como se advirtió respecto de las normas adscritas de derecho

\footnotetext{
${ }^{81}$ Bernal, cit. (n. 11), p. 100.

${ }^{82}$ Alexy, cit. (n. 12), p. 12.

${ }^{83}$ Bernal, cit. (n. 11), p. 499.
} 
fundamental, otra de las consecuencias de la ya mencionada indeterminación de las normas iusfundamentales, es que éstas suelen demandar una concreción, es decir, un acto institucional de adscripción consistente en aseverar ahora con carácter definitivo, el contenido de una disposición iusfundamental. Lo anterior para contar con una norma apta para la resolución de las cuestiones de derecho fundamental mediante la subsunción, condición de la que -de ordinario- carece en el orden de las disposiciones y de las normas directamente estatuidas de derecho fundamental.

En consecuencia, el control de constitucionalidad se mueve dentro del límite impuesto por esa cierta libertad de configuración del legislador o competencia de adscripción como actualización, por lo que habrían buenas razones para sostener que dicho control deba desplegarse sólo para indagar si la actualización de un derecho fundamental no importa transgredirlo; si al intentar armonizar uno o más derechos, alguno resulta vulnerado. Sólo así podrá romperse la presunción de constitucionalidad de los actos del legislador y desplegarse la competencia del Tribunal Constitucional.

Si bien es de la esencia de la función legislativa dotar de contenido y especificidad a las disposiciones constitucionales, entre ellas las iusfundamentales, no es menos cierto que ni siquiera la enorme legitimidad democrática de la que gozan los parlamentos y su tarea de concretar una opción entre las numerosas alternativas técnicas que se presentan, puede excusar o justificar una vulneración a la Carta Fundamental, que goza sustantivamente de una legitimidad aún mayor.

Pero no existen potestades sin control $^{84}$. Más específicamente, de la idea del Estado de Derecho brota la implica la convicción de que los poderes públicos -sin excepción- deben someterse al Derecho, para lo cual debe disponerse de los mecanismos de control judicial de las actuaciones estatales $^{85}$. La competencia de configuración termina al comenzar la competencia de control efectivo de la ley, mientras que dicha función termina donde comienza la libertad del legislador ${ }^{86}$. A la base de este principio se encuentra la protección de la separación de funciones, pero sobre todo una garantía que debe equilibrar la autonomía del Congreso y la supremacía constitucional.

\section{Las normas competenciales y los derechos fundamentales}

\footnotetext{
${ }^{84}$ Peredo, Marcela, El Margen de Apreciación del Legislador y el Test de Margen Proporcionado (Santiago, Thomson Reuters, 2018), p. 61.

${ }^{85}$ Martínez Estay, José Ignacio, Autorestricción, Deferencia y Margen de Apreciación, en Estudios Constitucionales 1 (2014), p. 367.

${ }^{86}$ Bernal, cit. (n. 11), p. 504.
} 
Los derechos y las libertades constituyen sólo un segmento de las posiciones llamadas derechos en sentido estricto ${ }^{87}$, es decir, aquello que está iusfundamentalmente permitido, prohibido u obligado. Otros de ellos pueden reconocerse por expresiones tales como poder o poder jurídico, competencia, autorización, facultad, derecho de configuración y capacidad jurídica ${ }^{88}$. Las posiciones que pertenecen a este grupo serán llamadas genéricamente competencias.

De esta primera apreciación, es importante destacar que las competencias son parte conceptual de los derechos fundamentales: ellos no sólo están constituidos por aquello que se encuentra subjetiva y iusfundamentalmente prohibido, permitido u obligado, sino que por aquello que está institucionalmente prohibido, permitido u obligado. Esto es lo que Aldunate entendería como comprensivo del ámbito normativo iusfundamental ${ }^{89}$.

Aquí se pone de relieve aquello que se juegan los órganos jurisdiccionales y reguladores en materia de derechos subjetivos: en la manera en que razonan, en que argumentan y mediante las prescripciones que emanan de las competencias y que se contienen en las normas que dictan, los órganos públicos modifican la situación iusfundamental de los individuos. Esto es lo que se denomina acciones institucionales ${ }^{90}$, es decir, de aquellas que pueden llevarse a cabo tanto por ciertas condiciones naturales para su realización -en el sentido de materialización- como debido a la presuposición de reglas que para la institución de que se trate son constituyentes.

Son distintas -desde luego- las normas competenciales y las normas de conducta o protectivas ${ }^{91}$, a saber, aquellas que normalmente componen el ordenamiento iusfundamental. Las normas de competencia crean la posibilidad de actos jurídicos y con ello la capacidad de modificar posiciones jurídicas iusfundamentales, mientras que las normas de comportamiento califican acciones al estatuir obligaciones, derechos a algo y libertades ${ }^{92}$. La distinción entre normas de comportamiento y normas de competencia se percibe con especial claridad en el caso de su incumplimiento. La inobservancia de una norma de competencia no conduce a la ilicitud, como en el caso de las normas de conducta, sino a la nulidad o a la deficiencia del acto.

Entre las competencias, se encuentra el asunto de la discrecionalidad legislativa93. Para Alexy la discrecionalidad legislativa es de dos tipos, sus-

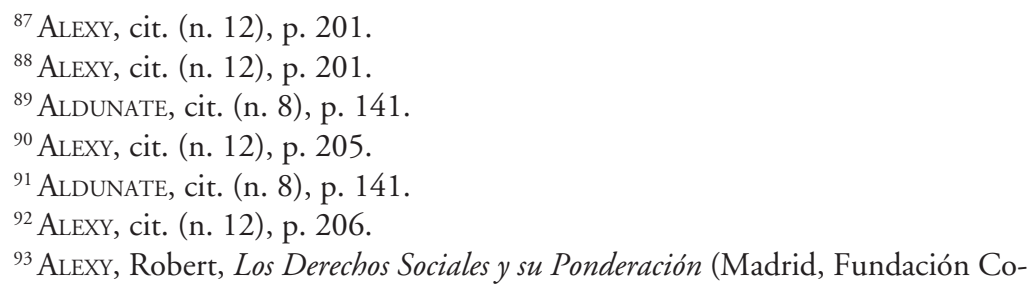


tantiva y epistémica. La discrecionalidad sustancial consiste en la capacidad jurídica para regular en todo aquello que las normas constitucionales ni ordenan ni prohíben, plataforma en la que se posa la libertad de configuración. La discrecionalidad epistémica - mientras tanto-consiste en la competencia para determinar, en casos de incertidumbre, lo que ordenan o prohíben las normas constitucionales, y lo que dejan libre ${ }^{94}$. Habría que agregar que la discrecionalidad epistémica incluye la libertad para definir el procedimiento mediante el cual se arriba legítimamente a una conclusión.

\section{LAS NORMAS COMPETENCIALES: UNA PROPUESTA COMO CONCLUSIÓN}

El alcance de la competencia o poder que se viene analizando, el del Parlamento, equivale al alcance de la correspondiente falta de competencia del Tribunal Constitucional. Es decir, que no existiría espacio para la acción del Tribunal Constitucional en aquello que se comprenda dentro de la discrecionalidad sustancial del Congreso. En dicho caso, a ese órgano le estaría vedado enjuiciar los medios elegidos, los fines y la ponderación hecha por el legislador con ocasión del establecimiento de una regulación de naturaleza iusfundamental.

Buenas razones militan a favor de extender este coto vedado también a los elementos de la discrecionalidad epistémica, es decir, que el Tribunal Constitucional no tendrá competencia para declarar la inconstitucionalidad de una norma legal debido a que no comparta el procedimiento elegido por el Parlamento para arribar a la conclusión que lo llevó a modelar el contenido de la ley. Aquí el Tribunal Constitucional sólo podrá constatar el uso de un procedimiento y -por otra parte- que la aplicación de aquel haya sido seria al mismo tiempo que no arbitraria. Los motivos para esta afirmación, son -con todo- muy sencillos. Si los derechos fundamentales -en el sentido normativo de la expresión-, tienen simultáneamente un contenido sustantivo y otro institucional, y es un hecho indisputado que el Tribunal Constitucional no puede pronunciarse sobre el mérito del contenido protectivo de un precepto legal, debido a que ello forma parte de la competencia iusfundamental del legislador, es esa misma razón la que impide pronunciarse sobre la manera en la que materializó la argumentación para fijar el contenido del referido precepto legal. En ambos casos,

loquio Jurídico Europeo, 2009), p. 79.

${ }^{94}$ Para Alexy, la discrecionalidad sustancial es mucho menos problemática que la epistémica. Que el poder legislativo goce de libertad allí donde la constitución no contemple obligaciones relevantes no precisa justificación alguna. Por el contrario, el que disponga de competencia de decisión cuando se plantee si goza o no de libertad ya no es tan evidente. 
en lo sustantivo y-como en la especie- en lo institucional, abocarse a una tarea iusfundamental que le corresponde a otra agencia estatal, importa vulnerar la Constitución en sentido orgánico pero también en sentido iusfundamental. Cuando el Tribunal Constitucional se avoca a las tareas iusfundamentales que constitucionalmente le corresponden al Congreso, vulnera los derechos fundamentales que está llamado a preservar.

Como se advierte, la falta de avocación del Tribunal Constitucional a los asuntos cercados por la libertad de configuración del legislativo, no se fundarían en razones de deferencia política a sus funciones ${ }^{95}$ sino a la cuestión jurídica iusfundamental de la competencia. Aquí la competencia del Tribunal Constitucional de auscultar que el legislador no ejerza más competencias que aquellas que la Constitución le ha encomendado y que cada una de ellas se ejerza con apego a las mismas normas de máxima jerarquía, se funda en razones epistémicas consistentes en la inexistencia de una vía alternativa para constatar que se está ante los límites de su competencia.

Así las cosas, queda de manifiesto que para deslindar la extensión de la facultad de configuración del legislador - por una parte- y la habilidad del Tribunal Constitucional para diagnosticar la constitucionalidad de las normas -por otra-, quizás más bien para dirimir la tirantez entre ellas, resulta pertinente para el derecho la perspectiva competencial. Ella entrega herramientas técnicas, de contornos más concretos y mejor organizados, toda vez que se conceptualiza con esmero y detención la discrecionalidad. Realizar esta tarea -por el contrario- desde la deferencia, es conformarse con un sucedáneo del constitucionalismo, más cercano a una renuncia -al encogimiento de hombros- que al ejercicio de una función pública ${ }^{96}$.

\section{Notas sobre la deferencia razonada}

Si se revisan las dos acepciones del concepto de deferencia razonada ${ }^{97}$, se advertirá que se trata de un instituto de incuestionable caris político. La primera de ellas, que se fundan en que los poderes públicos se deben una actitud de respeto y cortesía. No deben menospreciarse las formas de la República. Sus prácticas y concepciones inmateriales, tienen un enorme valor estabilizador de las conductas de los agentes públicos. Sin embargo, un quehacer como el que aquí incumbe demanda tener a disposición herramientas de genuinamente jurídicas, es decir, de la naturaleza de la tarea del Tribunal Constitucional. Si no se ha dicho con claridad, para obtener una respuesta que dé garantías de juridicidad, es una herramienta

${ }^{95} V$. gr., Zapata, Patricio, Justicia Constitucional (Santiago, Editorial Jurídica de Chile, 2008), pp. 225 y ss.

${ }^{96}$ LeIVA, cit. (n. 4), p. 96.

${ }^{97}$ ZaPATA, cit. (n. 95), p. 227. 
jurídica la que debe emplearse. Si lo que se utiliza para dicha faena es una herramienta de naturaleza política, una respuesta de esas características es lo que debe esperarse.

La segunda acepción, supone el reconocimiento y respeto de las competencias, en cuyo marco se tiene derecho a tomar decisiones con relativa autonomía. Aquí, en efecto se advierte una cierta coincidencia con lo que se viene planteando. Pero el defecto de la deferencia razonada no es teleológico, sino epistémico.

Mirado desde cerca, la deferencia razonada es ciertamente armónica con la separación de funciones, pero entraña una ausencia de densidad técnica que le permita determinar sobre qué y dentro de qué límites debe exigirse deferencia. Sin sufragar respuestas tan urgentes como esas, resulta imposible afirmar que -desde una perspectiva racional- sea genuinamente útil. Dicho lo anterior de otra manera, alguien que pida su auxilio para vedar la avocación de funciones, tendrá en ella una regla a la que todo puede concordarse al mismo tiempo que también puede hacerse discordar ${ }^{98}$; allí no habría -por lo tanto- un problema de concordia ni de discordia con tal regla, sino que no habría regla en lo absoluto. Esto es lo que se afirma aquí: la deferencia razonada no es una regla para dirimir la competencia entre el Congreso y el Tribunal Constitucional.

\section{La ponderación como regla competencial}

Cuando sea puesto en sede constitucional el debate jurídico sobre el exceso en el despliegue de las competencias del Parlamento, el Tribunal Constitucional deberá analizar con especial cuidado jurídico y no político, que no se haya sobrepasado ni un ápice su autonomía reguladora, es decir, que defina los medios, los fines y que realice una ponderación -en el sentido de la proporcionalidad-con estricto apego a la Carta Fundamental ${ }^{99}$.

Fijando el propio Parlamento los límites de la competencia por una vía jurídica, no habrá lugar para el ejercicio por el Tribunal Constitucional de esas mismas funciones. Si él se excediera en ello, vulneraría el orden iusfundamental, pues -como se vio-, las competencias forman parte de la arquitectura conceptual de los derechos. Si el legislador (por el contrario) fija un medio que restringe los derechos fundamentales más allá de los límites establecidos por la Constitución; si le diera valor a un fin ilegítimo en clave iusfundamental (sobrepasando sus competencias); si eligiera una medida restrictiva a sabiendas que existe otra igualmente

${ }^{98}$ Wittgenstein, Ludwig, Investigaciones Filosóficas (Barcelona, Gredos, 2017), p. 180 .

${ }^{99}$ LeIVA, cit. (n. 4), p. 97. 
idónea pero menos lesiva, por ejemplo, el Tribunal Constitucional no podría abstenerse de ejercer el control de constitucionalidad, so pretexto de respetar las atribuciones de otros órganos. En tal caso se encontraría en un escenario ya no de exceso sino de defecto. A lo anterior habría que agregar que los órganos que nos ocupan -y ciertamente tampoco los que se omiten- tiene funciones tan extensas como para usurpar las de otro y de esa manera fracturar los derechos fundamentales ${ }^{100}$.

Una de las formas que puede tomar aquel exceso, es la afectación desproporcionada a uno o más derechos producto de una norma legal. Esto supone que la ley con efectos iusfundamentales, vale decir, la norma que especifica el contenido a los derechos fundamentales -lo que incluye la limitación de éstos-, tampoco es entendida como un mero acto de autoridad estatal, sin importar que sea la manifestación institucional de un órgano dotado de la alta o superior legitimidad democrática. Por el contrario, importa entender a la ley como un acto público que también debe satisfacer criterios de corrección -en el sentido que se ha venido usando el término-. Si adolece de un defecto como la desproporción, puede y debe ser objeto del control de constitucionalidad, que-incluso-le reste validez, esto es que -bajo ciertas condiciones- ceda ante otro derecho en un caso determinado si no supera el test de proporcionalidad.

La conclusión es simple. Primero, debido a la relación necesaria que existe entre el carácter de principios de los derechos fundamentales y la ponderación, el Parlamento debe aplicar dicho test para especificar las disposiciones iusfundamentales directamente estatuidas por la Constitución. Para ello, debe aplicar el test en plenitud y con corrección técnica. Hecho eso, en el escenario del control de constitucionalidad, al Tribunal Constitucional sólo le corresponde corroborar la aplicación de dicho examen. Sólo en el caso que una norma constitucional con carácter de principio se haya especificado en una ley sin el concurso de la proporcionalidad, el Tribunal Constitucional no sólo podrá sino que deberá realizar dicho examen.

Aquí debe recordarse, que en materia de proporcionalidad el Congreso, posee una incuestionable autonomía epistémica, en la forma de libertad de configuración. Respecto de la idoneidad, sólo le están vedados los fines explícitamente prohibidos ${ }^{101} \mathrm{o}$ los medios que de ningún modo contribuyan técnicamente a la obtención de un fin no prohibido ${ }^{102}$. Respecto de la necesidad, basta que la medida elegida por el legislador sea menos lesiva que otras igualmente idóneas en un o varias perspectivas, para satisfacer

\footnotetext{
${ }^{100}$ LeIVA, cit. (n. 4), p. 98.

${ }^{101}$ Bernal, cit. (n. 11), p.704.

${ }^{102}$ Bernal, cit. (n. 11), p.724.
} 
este estándar ${ }^{103}$. En cuanto a la ponderación o proporcionalidad en sentido estricto, su libertad configuradora es mayor en las intervenciones iusfundamentales de menor intensidad ${ }^{104}$.

Es aquí donde la Ponderación muestra su virtud comunicadora entre las competencias de los órganos bajo estudio. Ella, cuando sea pertinente su aplicación, a saber, cuando el Parlamento actualice -mediante una ley- una norma iusfundamental directamente estatuida que tenga en la Constitución la forma de principio, servirá como un estándar jurídico homogéneo que podrá ser monitoreado fácilmente por el Tribunal Constitucional. Lo anterior, tanto en la cuestión analítica de haber o no sido aplicado, como en el asunto epistémico de haberse desarrollado mínimamente de acuerdo a su estructura. Aquí ya no habrá lugar a los aprietos insalvables proveídos por la mera interpretación o por criterios políticos como la deferencia razonada, para fijar el contenido de los derechos fundamentales.

La Ponderación -si bien tiene sus propios desafíos- ya superó las asperezas de la interpretación. Ello es lo mismo que afirmar, que el control de constitucionalidad iusfundamental no se aborda ni se resuelve simplemente interpretando. La interpretación se ubica presidiendo la primera parte del proceso de adscripción: gracias a ella se obtienen las normalmente varias hipótesis comprendidas en su campo lógico y semántico. Pero es mediante la ponderación que se obtiene la mejor de ellas, en el sentido fáctico, jurídico y epistémico de la expresión.

Todo lo dicho anteriormente, tiene una expresión en punto al principio de la legitimidad, cual es el objetivo sistémico que se alcanza a partir de la adhesión a la virtud pública de la tarea. El Tribunal Constitucional, ha concebido su faena siempre sumido en la conciencia jurídica de estar inserto en un sistema del que el Parlamento también forma parte, en el que la dignidad y criticidad de su quehacer no le alcanza para ser superior que el de otro sino simplemente constituye una competencia que convive con otras que también la definen. Sin embargo, no ha contado con una herramienta de índole jurídica y densa técnicamente, que le permita asirse a ella en el desasosiego de las intensas disputas que se ventilan en su sede.

La supremacía constitucional, no puede ser entendida en el sentido de que controlar la constitucionalidad de la ley supere en importancia a la producción de una norma legal de contenido iusfundamental. Por lo tanto, donde el legislador haya deliberado - de veras- racionalmente sobre la constitucionalidad de la ley que brota de su obra y que ese razonamiento contenga la pretensión de ser correcto, es decir, que sea urdido desplegando

\footnotetext{
${ }^{103}$ BerNAL, cit. (n. 11), p.752.

${ }^{104}$ BerNAL, cit. (n. 11), p.805.
} 
su libertad configuradora sin restringir desproporcionadamente los derechos fundamentales, el Tribunal Constitucional no tendrá competencia para ejercer su oficio.

El interés vital común es lo que produce el apoyo mutuo. Esa constatación releva el perjuicio que causa una contienda cuando lo esencial es afirmarse y defenderse. De ello brota la necesidad de la disciplina, como evitación de los conflictos por la afirmación del orden. Ahí reside la raíz del Derecho: voluntad unitaria y ligadora al orden establecido ${ }^{105}$.

Es imposible exagerar el valor democrático de concebir al Congreso Nacional y al Tribunal Constitucional como partícipes y elementos de un mismo sistema, esto es, como instituciones cuya acción de darle contenido a los derechos fundamentales garantizados en la Constitución, los define a sí mismos, al tiempo que delinea al otro, mediante la coordinación en punto a un interés común -no adversarial-, distantes de representaciones excluyentes e insulares.

\section{BIBLIOGRAFÍA}

Aarnio, Aulis, Lo Racional como Razonable (Lima, Palestra Editores, 2016).

Aldunate Lizana, Eduardo, Derechos Fundamentales, (Santiago, Legal Publishig, 2008).

Aldunate Lizana, Eduardo, La Fuerza Normativa de la Constitución y el Sistema de Fuentes del Derecho, en Revista de Derecho de la Pontificia Universidad Católica de Valparaiso 32 (2009).

AleXY, Robert, El Concepto y la Validez del Derecho (Barcelona, Gedisa, 1994).

AleXY, Robert, Los Derechos Sociales y su Ponderación (Madrid, Fundación Coloquio Jurídico Europeo, 2009).

Alexy, Robert, Teoría de los Derechos Fundamentales (Madrid, Centro de Estudios

Políticos y Constitucionales, 2012).

Alexy, Robert, Teoría de la Argumentación Jurídica (Madrid, Centro de Estudios

Políticos y Constitucionales, 2014).

Atienza Manuel, Las Razones del Derecho (Lima, Palestra Editores, 2016).

Atria, Fernando, La Forma del Derecho (Madrid, Marcial Pons, 2016).

Bernal Pulido, Carlos, El Principio de Proporcionalidad y los Derechos Fundamentales

(Madrid, Centro de Estudios Políticos y Constitucionales, 2007).

Bernal Pulido, Carlos, La Doble Dimensión del Derecho (Lima, Palestra, 2011).

Bernal Pulido, Carlos, Estudio Introductorio a la Teoría de los Derechos Fundamentales

de Robert Alexy (Madrid, Centro de Estudios Públicos y Constitucionales, 2012).

BÄCKer, Carsten, Reglas, Principios y Derrotabilidad, en DOXA. 37 (2014).

BARak, Aharon, Proporcionalidad (Lima, Palestra Editores, 2017).

Clérico, Laura, Examen de Proporcionalidad en el Derecho Constitucional (Buenos

Aires, Ediciones Facultad de Derecho de la Universidad de Buenos Aires, 2009).

105 Tünnies, Ferdinand, Principios de Sociología (Granada, Comares, 2009), p. 168. 
DíAz, Iván, La Aplicación del Principio de Proporcionalidad en Orden a Juzgar sobre la Licitud o Ilicitud de una Restricción a Derechos Fundamentales, en Revista de Derecho de la Pontificia Universidad Católica de Valparaíso 36 (2011).

Dworkin, Ronald, Los Derechos en Serio (Barcelona, Ariel, 2012).

Habermas, Jürgen, Facticidad y Validez (Madrid, Trotta, 2010).

Henríquez Viñas, Miriam, Las Fuentes Formales del Derecho (Santiago, LegalPublishing, 2009).

Huerta Ochoa, Carla, Conflictos Normativos (México D.F, Universidad Nacional Autónoma de México, 2003).

LeIva, Antonio, Proporcionalidady Justicia Constitucional (Santiago, Libromar, 2018).

LeIva, Antonio, Corrección y Facticidad, en Revista de Derecho de la Universidad Católica de Uruguay 18 (2018) 2, pp. 139-164.

LeIva, Antonio, Deliberación Legislativa y Corrección: Un ensayo sobre la legislación iusfundamental como un quehacer regido por normas juridicas sustantivas, en Revista de Derecho Aplicado LLM UC 2 (2018).

MacCormick, Neil, Instituciones del Derecho (Madrid, Marcial Pons, 2011).

Martínez Estay, José Ignacio, Autorestricción, Deferencia y Margen de Apreciación, en Estudios Constitucionales 1 (2014).

Peredo, Marcela, El Margen de Apreciación del Legislador y el Test de Margen Proporcionado (Santiago, Thomson-Reuters, 2018).

Perelman, Chaïm y Olbrfecht-Tyteca, Lucie, Tratado de la Argumentación (Madrid, Gredos, 2017).

Soper, Philip, Una Teoría del Derecho (Madrid, Centro de Estudios Constitucionales, 1993).

Tünnies, Ferdinand, Principios de Sociología (Granada, Comares, 2009).

Wittgenstein, Ludwig, Tractatus Logico-Philosophicus/Investigaciones Filosóficas (Barcelona, Gredos, 2017).

Zagrebelsky, Gustavo, La Ley y su Justicia (Madrid, Trotta, 2014).

Zapata, Patricio, Justicia Constitucional (Santiago, Editorial Jurídica de Chile, 2008). 